\title{
CARTAS DEL PAÑERO
}

Jonathan Swift*

\author{
A los comerciantes, tenderos, agricultores y al pueblo \\ en generaldel Reino de Irlanda \\ (Primera carta)
}

En 1722, cuando Carlos duque de Grafton era virrey de Irlanda, William Wood, un ferretero en bancarrota, alegando la gran necesidad de monedas de cobre en ese reino, se procuró una patente para acuñar 108.000 libras, con el fin de que circularan como moneda corriente. El deán pensó que esta medida era una tarea vil de principio a fin y que quienes se habían procurado la patente se repartirían los beneficios que provendrían de la ruina del reino, y asumió la personalidad de un pañero, M. B. Drapier. En las siguientes cartas advirtió al pueblo que no recibiera la moneda que se le enviaría [Nota de los editores de la edición de 1801].

ermanos, amigos, compatriotas y compañeros súbditos.
Lo que hoy pretendo deciros es, junto a vuestro deber con Dios
y el cuidado de vuestra salvación, del mayor interés para vosotros y
vuestros hijos, pues vuestro pan, vuestro vestuario y toda necesidad
común de la vida dependen totalmente de ello. Por lo tanto, os exhorto
encarecidamente, como hombres, como cristianos, como padres y

* En 1724, Jonathan Swift redactó siete cartas contra el proyecto de acuñación de moneda de William Wood, firmadas por M. B. Drapier, que se conocen como "Cartas del pañero", y cuatro escritos adicionales. Las dos cartas que publicamos se tomaron de The works of the Rev. Jonathan Swift, vol. 9, "Drapier's letters", J. Nichols, ed., Londres, Baldwin and Son. Printers, 1801. Traducción de Alberto Supelano. Por los buenos oficios de Alberto Castrillón, miembro de nuestro comité editorial, el traductor pudo consultar tardíamente la traducción de Aránzazu Usandizaga, publicada por Bosch en 1982, en su colección de textos bilingües, que le ayudó a precisar algunas interpretaciones y a enmendar errores. Fecha de recepción: 2 de febrero de 2015, fecha de aceptación: 29 de abril de 2015. Sugerencia de citación: Swift, J. "Cartas del Pañero", Revista de Ecomonía Institucional 17, 32, 2015, pp. 351-374. DOI: 10.18601/01245996.v17n32.12 
como amantes de vuestro país, a leer este escrito con la mayor atención o a que pidáis a otras personas que os lo lean. Para que podáis hacerlo con el menor gasto ordené al impresor que lo venda a un precio mínimo.

Es un gran yerro que cuando una persona escribe sin otra intención que haceros el bien no os toméis la molestia de leer sus consejos. Una copia de este escrito puede servir para una docena de vosotros, así cuesta menos de un cuarto de penique por cabeza. Es una locura que no tengáis en mente el interés común o general, ni aun el más sensato de vosotros, ni sepáis ni averigüéis ni os importe quiénes son vuestros amigos o vuestros enemigos.

Hace unos cuatro años se escribió un librito que aconsejaba a todas las personas que usaran las manufacturas de este, nuestro querido país ${ }^{1}$. No tenía otro designio, nada decía contra el rey ni el parlamento, ni contra ninguna otra persona; pero el pobre impresor estuvo sometido a juicio durante dos años con la mayor violencia, e incluso algunos tejedores, en cuyo bien fue escrito, que eran parte del jurado, lo declararon culpable. Esto sería suficiente para desanimar a cualquier hombre que se empeñe en haceros el bien, cuando lo abandonáis u os burláis de sus penalidades, y solo le cabe esperar el peligro de ser multado y encarcelado, quizá hasta arruinarse.

Sin embargo, no puedo dejar de advertiros una vez más el desastre que os espera si no obráis como debéis.

Por ello, primero os contaré la historia llana del hecho y después os mostraré cómo debéis obrar, con sentido común y conforme a las leyes de vuestro país.

El hecho es este: como hace muchos años se acuñaron los últimos medios peniques y cuartos de penique de cobre en este reino, desde hace ya algún tiempo son muy escasos y circulan muchas monedas falsas con el nombre de $r a p$, se ha pedido varias veces a Inglaterra que nos dé libertad para acuñar monedas nuevas, como hacíamos en tiempos anteriores; sin tener éxito. Al fin, un tal señor Wood, un hombre común y corriente, ferretero, se procuró una patente con el gran sello de Su Majestad para acuñar 108.000 libras en cobre para este reino; aunque la patente no obligaba a nadie a aceptarlas, a menos que quisiera. Ahora debéis saber que el medio penique y los cuartos de penique circulan en Inglaterra por un poco más de lo que valen; y si los hicieseis pedazos y los vendieseis al chatarrero no perderíais más de un penique por chelín. Pero como el señor Wood hizo sus

\footnotetext{
${ }^{1}$ Una propuesta para el uso universal de manufacturas irlandesas [N. T.: escrita por el mismo Jonathan Swift en 1720].
} 
medios peniques con metal común y mucho más pequeños que los ingleses, el chatarrero apenas os daría más de un penique de buena moneda por uno de sus chelines; así, esta suma de 108.000 libras, en buen oro y buena plata, no es más que basura pues no tendrá un valor real de más de 8 o 9 mil libras. Y esto no es lo peor, pues cuando le plazca, el señor Wood puede enviar a hurtadillas otras 108.000 libras y comprar todos nuestros bienes por once doceavos menos de su valor. Por ejemplo, si un sombrerero vende una docena de sombreros a cinco chelines la pieza, lo que equivale a tres libras, y recibe el pago en la moneda de Wood, en realidad solo recibe el valor de cinco chelines.

Quizá os preguntéis por qué una persona tan común y corriente como este señor Wood pudo ganar influjo para obtener el gran sello de Su Majestad y enviar tan alta suma de dinero malo a este pobre país, y que nuestra nobleza y nuestra alta clase no hayan podido obtener ese favor y se nos deje hacer nuestros propios medios peniques, como solíamos hacer. Os responderé llanamente: estamos lejos de la corte del rey y no tenemos a nadie que vele por nosotros, aunque un gran número de lores y señores irlandeses que tienen aquí sus propiedades viven y gastan allí su fortuna. En cambio, el señor Wood cuida continuamente su propio interés; es inglés, tiene grandes amigos y, al parecer, supo muy bien a quienes dar dinero para que hablaran con otros que intercediesen por él ante el rey. Y Su Majestad, o el gran Lord o los lores que lo aconsejaron, quizá creyeron que era algo benéfico para nuestro país; y así, como lo expresan los abogados, el rey concedió la patente con engaño, como suele suceder en todos los reinos. Estoy seguro de que si Su Majestad supiese que si dicha patente se llevara a efecto según el deseo del señor Wood arruinaría completamente a este reino, que tan grandes pruebas de lealtad le ha dado, la revocaría de inmediato y mostraría su disgusto con alguno de sus cortesanos, porque al buen entendedor le bastan pocas palabras. Muchos de vosotros os habréis enterado de que nuestra honorable Cámara de los Comunes recibió con indignación el aviso de la patente de Wood. Allí se presentaron buenos argumentos y pruebas claras de que era una trampa engañosa de principio a fin, y después se publicaron unas declaraciones inteligentes a las que Wood se atrevió a responder también por escrito, con tono arrogante, como si fuese un hombre mejor que todos los de nuestro parlamento.

Tan pronto se aprobó su patente, o algo después, Wood envió en barriles esos medios peniques a Corck y a otros puertos de mar, y para ponerlos en circulación ofreció cien libras de su moneda a cambio 
de setenta u ochenta de plata: pero los recaudadores de la aduana del rey muy honestamente se negaron a aceptarlos, como se negaron casi todos los demás. Y puesto que el parlamento los reprobó y pide al rey que impida su circulación, todo el reino los repudia.

Pero Wood sigue obrando a hurtadillas para imponernos sus medios peniques, y cree que logrará su propósito si con ayuda de sus amigos de Inglaterra logra conseguir una orden para que los comisionados y los recaudadores del tesoro real los reciban y con ellos se pague al ejército. En tal caso afrontaréis la siguiente dificultad: cuando un soldado común vaya al mercado o a la taberna ofrecerá estas monedas, y si se las rechazan tal vez lance bravatas e intimidaciones y amenace con golpear al carnicero o al tabernero o llevarse los bienes a la fuerza, y les arroje los medios peniques malos. En este caso y en casos parecidos, el tendero, el proveedor o cualquier otro comerciante no puede hacer más que exigir diez veces el precio de sus bienes cuando se pagan con la moneda de Wood; por ejemplo, veinte peniques en esa moneda por un cuarto de galón de cerveza y así en todo lo demás, sin entregar los bienes hasta que se reciba el dinero.

Suponed que vais a la taberna con esas monedas y que el propietario os da un cuarto de galón por cuatro de esos medios peniques: ¿qué hará el proveedor? El cervecero no aceptará que le pague con esas monedas, o si es tan necio que las acepta los agricultores no se las recibirán a cambio de su cebada, porque su contrato los obliga a pagar la renta en moneda inglesa buena y legal, y estas no lo son, como tampoco las de Irlanda; y el terrateniente, su señor, nunca será tan cándido que acepte esa basura por sus tierras; de modo que dejará de circular en alguna parte, no importa dónde pues todos estaremos en la ruina.

El peso común de estos medios peniques es de cuatro a cinco por onza, digamos cinco; así, tres chelines y cuatro peniques pesarán una libra y, por tanto, veinte chelines pesarán el equivalente a seis libras de dieciocho onzas. Ahora bien, cientos de agricultores pagan doscientas libras de renta al año, y cuando uno de ellos vaya a pagar la renta de medio año, cien libras, tendrá al menos seiscientas libras de peso, la carga de tres caballos.

$\mathrm{Si}$ un terrateniente piensa venir a la ciudad a comprar ropas, vino y especias para él y su familia, o a pasar aquí el invierno, tendrá que traer cinco o seis caballos cargados de sacos, así como los agricultores traen su grano, y cuando su señora venga en carruaje a nuestras tiendas, tendrá que seguirla un coche repleto de monedas del señor 
Wood. Y espero que tengamos la gentileza de no aceptarlas por más de lo que valen.

Dicen que William Conolly ${ }^{2}$ obtiene 16.000 libras al año; si envía su renta a la ciudad, como es probable que lo haga, necesitará 250 caballos para cargar la renta de medio año, y dos o tres bodegas grandes en su casa para almacenarla. No puedo decir qué harán los banqueros, pues me aseguran que algunos grandes banqueros mantienen 40.000 libras en moneda constante y sonante para cumplir todos los pagos; suma que, en la moneda del señor Wood, requeriría 1.200 caballos para cargarla.

Por mi parte, ya resolví qué hacer: tengo una buena tienda de paños y sedas irlandesas, y en vez de aceptar el cobre malo del señor Wood, pienso intercambiar bienes por bienes con mis vecinos, los carniceros, panaderos y cerveceros, y con todos los demás. Y conservar la pequeña cantidad de oro y plata que poseo como la sangre de mi corazón hasta tiempos mejores o hasta que esté a punto de morir de hambre; entonces compraré la moneda del señor Wood como hizo mi padre con la moneda de bronce en tiempos del rey Jaime, que pudo comprar diez libras de esa moneda con una guinea. Yo espero obtener mucho más por un doblón de oro y así comprar pan a quienes sean lo bastante necios para vendérmelo.

Si estos medios peniques llegasen a circular pronto serán falsificados, porque el metal es tan bajo que es muy barato falsificarlos. Es probable que los holandeses hagan lo mismo y nos los envíen en pago de nuestros bienes; el señor Wood nunca tendrá reposo y seguirá acuñando, de modo que en algunos años tendremos al menos 108.000 libras multiplicadas por cinco de esta chatarra. Se presume que la moneda que hoy circula en este reino no pasa de 400.000 libras en total, y mientras quede una moneda de plata de seis peniques estos chupasangres no tendrán reposo.

Os diré cuál será el final una vez el reino sea reducido a dicha situación: los dueños de tierras desalojarán a sus arrendatarios por falta de pago, porque, como os dije antes, estos están obligados a pagar el arrendamiento en libras esterlinas, la moneda de circulación legal en Inglaterra. Luego expulsarán a sus propios agricultores, como muchos ya lo hacen, criarán ovejas donde puedan y solo conservarán el resto de ganado necesario, luego se convertirán en sus propios comerciantes y enviarán su lana y su mantequilla, sus cueros y su lino allende el mar, a cambio de dinero en metálico, vino, especias y sedas. Solo mantendrán algunos aldeanos miserables. Los agricultores tendrán

\footnotetext{
${ }^{2}$ Entonces vocero de la Cámara de los Comunes.
} 
que robar o mendigar, o irse del país. Los tenderos de este y de todos los pueblos quebrarán y morirán de hambre, porque el dueño de la tierra es el que mantiene al comerciante, al tendero y al artesano.

Pero cuando el terrateniente se convierta en agricultor y comerciante, atesorará toda la moneda buena que reciba del extranjero para enviarla a Inglaterra, y en su casa apenas mantendrá un tejedor o un sastre pobre o alguien semejante, que estará feliz de conseguir pan sea como sea.

Jamás acabaría si os dijera todas las miserias que sufriremos si fuésemos tan necios y obtusos que aceptásemos esta moneda maldita. Si toda Irlanda se pusiese en un lado de la balanza y este lamentable Wood en el otro sería muy difícil que él pesara lo que pesa el reino entero, que cada año pone en los bolsillos de Inglaterra más de 1.000.000 en libras de buena moneda, más de lo que los ingleses se embolsillan del resto del mundo.

Pero vuestro gran consuelo es que así como la patente de $\mathrm{Su}$ Majestad no os obliga a aceptar esta moneda, las leyes no le han dado a la corona el poder para obligar a sus súbditos a aceptar la moneda que al rey le plazca. Si no fuese así se nos podría obligar a aceptar pedruscos, conchas marinas o cuero con sellos como moneda corriente si alguna vez tuviésemos que vivir bajo el gobierno de un mal príncipe, que si tuviese ese poder, podría hacer pasar una guinea por diez libras, un chelín por veinte chelines, etc., con lo que en corto tiempo se apoderaría de todo el oro y la plata del reino, sin dejarnos más que bronce o cuero, o lo que le placiera. Nada se considera más cruel y opresivo que la práctica común del gobierno francés de recoger toda su moneda después de depreciarla mucho y luego acuñar una nueva a un valor mayor. Esta práctica es, sin embargo, mil veces menos perversa que este repudiable proyecto del señor Wood, porque los franceses dan plata por plata y oro por oro a sus súbditos, mientras que este individuo ni siquiera nos dará bronce o cobre de buena aleación por nuestro oro y nuestra plata, ni a la doceava parte de su valor.

Luego de haberos dicho todo esto, ahora os transmitiré el concepto de algunos eminentes abogados sobre esta materia, a quienes pagué en vuestro provecho para que me dieran sus opiniones por escrito; por ello estoy seguro que os expondré razones bien fundamentadas.

Un famoso libro de derecho, llamado El espejo de la justicia, que trata de las cartas (o leyes) promulgadas por nuestros antiguos reyes, describe así la ley: ordenó que ningún rey de este dominio podría cambiar o deteriorar la moneda, o estampar otra moneda que no fuera 
de oro o plata, sin el consentimiento de todos los condados; es decir, sin consentimiento del parlamento, como dice Lord Coke ${ }^{3}$.

Este libro es muy antiguo, y de gran autoridad en la época en que fue escrito; por esa razón lo cita a menudo el gran abogado Lord $\mathrm{Coke}^{4}$. Por las leyes de Inglaterra los diversos metales se dividen en metales legales o verdaderos, y metales ilegales o falsos; los primeros comprenden la plata y el oro; los segundos, los metales más viles. La orden de que solo los primeros se empleen en los pagos figura en un acta del parlamento ${ }^{5}$, aprobada el vigésimo año del reinado de Eduardo I, llamada "Estatuto sobre la circulación de peniques", que aquí os presento traducida a nuestra lengua pues, como me han dicho, algunas de nuestras leyes de aquel tiempo se escribieron en latín: "Quienquiera que al comprar o vender ose rechazar medio penique o un cuarto de penique de moneda legal, que tenga el sello que ha de llevar, será apresado por desacato a la majestad del rey, y llevado a prisión".

Conforme a este estatuto, solo se puede considerar que una persona desacata la majestad del rey, y enviarla a prisión por ese crimen, si se niega a aceptar la moneda real hecha de metal legal, que como observé antes solo comprende la plata y el oro.

Que esta es la verdadera interpretación del acta es evidente no solo en el significado llano de las palabras, sino en el comentario de Lord Coke sobre el acta ${ }^{6}$. Según esta ley (dice él), es claro que ningún súbdito puede ser obligado a aceptar, en una compra o una venta o en otros pagos, una moneda que no sea de metal legal, es decir, de plata o de oro.

La ley de Inglaterra da al rey todas las minas de oro y plata, pero no las minas de otros metales; como explica Lord Coke ${ }^{7}$, la razón de esa prerrogativa o poder es que se pueden hacer monedas de oro y plata pero no de otros metales.

Conforme a esta opinión, los medios peniques y los cuartos de penique antiguamente se hacían de plata, lo que es evidente en el acta del parlamento del reinado de Enrique IV, cap. 4, por la cual se aprobó el siguiente artículo: "Debido a la gran escasez de medios peniques y cuartos de penique de plata que hoy se presenta en el reino de Ingla-

${ }^{3}$ E. Coke, Institutes of the Lawes of England, primera parte, Londres, impreso por Adam Islip, , 1628 p. 576.

${ }^{4} \mathrm{E}$. Coke, Institutes of the Lawes of England, segunda parte, Londres, impreso por M. Flesher y R. Young para varios libreros de Fleetstreet y Holborn, 1669, p. $576, \S 7$.

${ }^{5}$ Ibíd., 577.

${ }^{6}$ Ibíd., 577.

7 Ibíd., 577. 
terra, se ordena y se decreta que la tercera parte de toda la moneda de chapa de plata se lleve a lingotes y se convierta en medios peniques y cuartos de penique". Esto demuestra que las palabras medio penique y cuarto de penique de moneda legal del estatuto sobre la circulación de peniques se refieren a una pequeña moneda de medio penique y de un cuarto de penique de plata.

Esto es aún más manifiesto en el estatuto del noveno año de reinado de Eduardo III, cap. 3, que promulgó: "Ni los plateros ni ninguna otra persona pueden fundir medios peniques ni cuartos de penique para hacer vasijas $u$ otros objetos, so pena de confiscación de la moneda fundida".

Por medio de otra ley de este reinado, la moneda negra no podía circular en Inglaterra. Y una ley del decimoprimer año de su reinado, cap. 5, prohibió la circulación de los medios peniques de galeras. No sé qué clase de monedas eran esas, pero supongo que estaban hechas de metal vil. $Y$ estas leyes no eran leyes nuevas, sino ampliaciones de las antiguas leyes concernientes a la moneda.

Esta es la ley en vigor con respecto a la moneda, y no hay ejemplos que la contradigan, salvo uno en los Informes de Davis, quien nos cuenta que en la época de la rebelión de Tyrone, la reina Isabel ordenó acuñar moneda de aleaciones de metal en la Torre de Londres y enviarla aquí para pagar al ejército, y que se obligara a todo el pueblo a recibirla; dispuso además que toda moneda de plata solo se valorara en lingotes, es decir, por lo que pesaba. Davis nos cuenta varios detalles de este asunto, pero son demasiado largos y no os quiero fatigar; entre ellos que el consejo privado de este reino obligó a un comerciante de Inglaterra a recibir esta moneda de aleación en pago de algunos bienes que envió a Irlanda.

Pero los mejores abogados rechazan este procedimiento; como es contrario a la ley, el consejo privado no tiene esa facultad legal. Y, además, se debe considerar que la reina estaba entonces en graves dificultades por la rebelión en este reino apoyada por España. Y lo que se haga en tiempos de peligro y de grandes exigencias nunca debería ser un ejemplo para proceder en épocas de paz y tranquilidad.

Queridos amigos, para ahorraros la molestia, resumiré lo que la ley os obliga a hacer y lo que no os obliga.

Primero, estáis obligados a recibir como pago toda moneda acuñada por el rey si cumple la norma o el peso inglés, siempre que sea de oro o plata.

Segundo, no estáis obligados a aceptar monedas que no sean de oro o plata, no solo los medios peniques o cuartos de penique de In- 
glaterra, sino las de ningún otro país. Y solo os convendrá recibirlas por conveniencia o por comodidad, pues hace mucho tiempo que se dejaron de acuñar medios peniques y cuartos de penique de plata, supongo que debido a que se pueden perder.

Tercero, mucho menos estamos obligados a aceptar los medios peniques viles del mencionado Wood, con los que perderíais casi once peniques por chelín.

En vista de ello, amigos míos, todos os debéis oponer, y rechazar esta repugnante basura. No es traición rebelarse contra el señor Wood. En su patente, Su Majestad no obliga a nadie a aceptar estos medios peniques: nuestro gracioso príncipe no tiene tan malos consejeros en la corte, o si los tuviese, como habéis visto, las leyes no dan al rey la facultad para obligarnos a aceptar cualquier moneda excepto la que es legal y cumple la norma, de oro y plata. Por ello nada tenéis que temer.

Permitidme ahora dirigirme en particular a vosotros, los comerciantes más pobres. Quizá penséis que si estos medios peniques llegaran a circular no perderéis tanto como los ricos porque rara vez veis plata, y los clientes que van a vuestras tiendas o casetas solo llevan bronce, el que os es igualmente difícil conseguir. Pero podéis confiar en mi palabra: si aceptáis esta moneda quedaréis en la ruina. Si lleváis estos medios peniques a una tienda para comprar tabaco o brandy, u otra cosa que queráis, el tendero os dará los bienes según su precio o quebrará y cerrará la tienda. ¿Creéis que os venderé una yarda de tela de diez peniques por veinte medios peniques del señor Wood? No, ni por menos de doscientos, como mínimo, y no me molestaré en contarlos sino que los pesaré en bulto. Os diré algo más, si el proyecto del señor Wood prospera arruinará incluso a nuestros mendigos, porque cuando doy medio penique a un mendigo, apagará su sed o encontrará una buena manera de llenar el vientre, pero la doceava parte de medio penique no le servirá más que si le diera tres alfileres de mi manga.

En resumen, estos medios peniques son como el objeto maldito que, según nos dicen las Escrituras, se les prohibía tocar a los hijos de Israel. Se esparcirán como la plaga y destruirán a todo el que los toque. He oído que los eruditos hablan de un hombre que le dijo al rey que había inventado una manera de atormentar a las personas metiéndolas en un toro de bronce sobre fuego ardiente, pero el príncipe metió primero al inventor en el toro de bronce para hacer el experimento. Esto se parece mucho al proyecto del señor Wood, y puede ser posible que el destino del señor Wood sea similar, que el 
bronce que inventó para atormentar a este reino resulte ser su propio tormento y, al final, su destrucción.

N.B. El autor de este escrito ha sido informado por personas que en su negocio han hecho observaciones tan exactas del verdadero valor de estos medios peniques que cualquier persona puede esperar comprar un cuarto de galón de cerveza de dos peniques por treinta $\mathrm{y}$ seis de esos medios peniques.

Deseo que todas las familias conserven cuidadosamente este escrito para refrescar su memoria cuando tengan nuevo aviso de los medios peniques del señor Wood o de cualquier impostura semejante.

M. B. Drapier

1724

\section{A todo el pueblo de Irlanda (Cuarta carta)}

Mis queridos compatriotas,

Después de escribir tres cartas sobre un tema tan desagradable como el del señor Wood y su medio penique, creí haber terminado mi tarea. Pero veo que a las constituciones débiles, políticas y naturales, se les debe aplicar con frecuencia tónicos fortificantes. Un pueblo largamente acostumbrado a las adversidades pierde poco a poco la noción de libertad y cree estar a merced de los demás; y, en palabras del Informe, que es legal y obligatorio todo lo que le impone una mano más fuerte. De ahí proviene esa pobreza y cortedad de espíritu a la que puede estar sometido un reino o una persona particular. Y no es sorprendente que Esaú vendiera su primogenitura por un plato de lentejas cuando volvió del campo muerto de hambre.

Pensé que había mostrado suficientemente a todos los que quisieran instruirse los métodos que podían emplear sin peligro cuando les ofrecieran esta moneda, $y$ creo que en mucho tiempo no ha habido un ejemplo de un reino tan firmemente unido en un punto de gran importancia como hoy lo está el nuestro contra ese detestable fraude. Sin embargo, ocurre que algunas personas débiles empiezan a alarmarse de nuevo por rumores laboriosamente difundidos. Wood prescribe lo que tienen que escribir a los pregoneros de noticias de Londres. En uno de sus escritos, publicado aquí por un oscuro impresor (y, por cierto, con mala intención), nos dice que los papistas de Irlanda se asociaron contra su moneda, aunque es de sobra conocido que jamás se han ofrecido a intervenir en el asunto. Así, bajo el nombre de papistas se estigmatiza en bloque a las dos cámaras del parlamento, 
al consejo privado, al gran número de corporaciones, al alcalde y a los concejales de Dublín, a los grandes jurados y a los principales caballeros de varios condados.

Este impostor y sus secuaces también dicen que al negarnos a aceptar su escoria como moneda esterlina impugnamos la prerrogativa del rey, que estamos maduros para iniciar la rebelión y dispuestos a liberarnos de la dependencia de Irlanda ante la corona de Inglaterra. Para apoyar esta información publicó en otro periódico un párrafo que nos avisa que se ordenó al virrey que viniese de inmediato a imponer su medio penique.

Os ruego, queridos compatriotas, que no os preocupéis lo más mínimo por este rumor ni por rumores semejantes, que no son más que los últimos ladridos de un perro disecado en vida, como espero que así haya sido. Estas calumnias son la única reserva que le queda. Porque seguramente nunca se pondrá en cuestión nuestra lealtad continua y (casi) sin ejemplo para impedir que un oscuro ferretero nos robe todo lo que poseemos.

En cuanto a que impugnamos la prerrogativa del rey, permitidme explicar el significado de la palabra prerrogativa a quienes lo ignoren.

Los reyes de estos dominios gozan de varias facultades a las que no se han interpuesto las leyes. Pueden hacer la guerra y la paz sin el consentimiento del parlamento, y esta es de veras una gran prerrogativa, pero si el parlamento no aprueba la guerra, el rey debe pagarla de su propio bolsillo, y este es un gran freno a la corona. Asimismo, el rey tiene la prerrogativa de acuñar moneda sin el consentimiento del parlamento, pero no puede obligar a sus súbditos a aceptar esa moneda excepto que sean libras esterlinas, de oro o plata, porque en esta materia está limitado por la ley. Algunos príncipes han extendido su prerrogativa más allá de lo que la ley les permitía; si bien en estos casos los abogados de épocas sucesivas, por su inclinación a consultar los precedentes, no se han atrevido a justificarlos. Pero a decir verdad, esa prerrogativa solo se estableció y se aclaró en los últimos tiempos. Pues quien lea la historia de Inglaterra verá que algunos reyes antiguos, y no los peores, se atrevieron a manipular las leyes con muy poca ceremonia y pocos escrúpulos, aun después de la época de la reina Isabel. En su reinado, ese perjudicial consejo de enviarnos moneda de baja aleación casi la lleva a perder este reino; ante las quejas del Lord delegado, el consejo y todos los ingleses de aquí, poco después de su muerte su sucesor revocó la orden y se volvió a la moneda legal.

Después de dar una idea del significado de la prerrogativa del rey, hasta donde es capaz de explicarlo un comerciante, solo añadiré la 
opinión del gran Lord Bacon: "Así como Dios gobierna el mundo conforme a las leyes de la naturaleza que él creó y solo trasciende esas leyes en ocasiones excepcionales, así, entre los príncipes terrenales, los mejores y más sabios gobiernan conforme a las leyes conocidas del país y rara vez hacen uso de su prerrogativa”.

Podéis ver ahora que no hay lugar a la vil acusación de Wood y sus cómplices, que nos culpan de impugnar la prerrogativa del rey por rechazar su cobre, pues no es parte de la prerrogativa obligar a los súbditos a que acepten una moneda que no sea esterlina. Además, estoy seguro de que, si lo fuese, seríamos el último pueblo en impugnarla, bien sea por la inquebrantable lealtad que siempre hemos prestado a Su Majestad o por el trato que nos cabría esperar en tal caso por parte de quienes parecen creer que no tenemos sentido común ni sentimientos comunes. Pero, gracias a Dios, los mejores de ellos solo son compañeros súbditos y no nuestros amos. Estoy seguro de que tenemos un gran mérito del que no pueden pretender los ingleses de nacimiento: nuestros ancestros sometieron este reino a la obediencia a Inglaterra; por ellos hemos sido recompensados con un clima peor, con el privilegio de que se nos gobierne con leyes a las que no damos consentimiento, con un comercio ruinoso, una cámara de pares sin jurisdicción, la casi total incapacidad para conseguir cargos y el temor al medio penique de Wood.

Pero estamos tan lejos de impugnar la prerrogativa de acuñación del rey que reconocemos su facultad de dar a cualquier persona una patente para que estampe su imagen y su inscripción real en el material que le plazca, y la libertad del titular de la patente para ofrecer las monedas en cualquier país, desde Inglaterra hasta Japón, con la pequeña limitación de que ningún ser vivo está obligado a aceptarlas.

Basado en estas consideraciones siempre me opuse a recurrir a Inglaterra para remediar este mal inminente, en especial cuando observé que la apelación a ambas cámaras, después de larga espera, solo produjo un informe del todo favorable a Wood, el cual ya comenté en una carta anterior, y sobre el cual podría haber hecho más comentarios porque es un escrito de un carácter tan singular como jamás he visto.

Pero me equivoco, porque antes de hacer este informe, se envió y se imprimió aquí la gentil respuesta de Su Majestad a la Cámara de los Lores, en la que constan las siguientes palabras; "otorgar la patente para acuñar medios peniques y cuartos de penique, conforme a la práctica de sus reales predecesores, etc.”. Es indiscutible que el rey Carlos II y el rey Jaime II (y solo ellos) concedieron patentes para este propósito, y ya lo comenté extensamente. Sus patentes se aprobaron 
con el gran sello de Irlanda, con inscripciones de Irlanda, y el cobre se debía acuñar en Irlanda. El titular de la patente estaba obligado, si se le pedía, a aceptar su moneda en Irlanda y a cambio pagar en oro y plata. La patente de Wood lleva el gran sello de Inglaterra, el cobre se acuña en Inglaterra, sin inscripciones de Irlanda; la suma es inmensa y el titular no está obligado a recibir de nuevo sus monedas a cambio de moneda legal. Menciono esto porque, en mis pensamientos íntimos, me he preguntado si el redactor de las palabras "conforme a la práctica de su reales predecesores" de la gentil respuesta de $\mathrm{Su}$ Majestad consideró atentamente las diversas circunstancias que, en mi modesta opinión, parecen marcar una diferencia.

Permitid que ahora me refiera a la otra gran causa del temor de algunas personas, que el periodista de Londres difundió por instrucción de Wood: que Su Excelencia el virrey viene a imponer los medios peniques de Wood.

Sabemos muy bien que desde hace años los señores virreyes no creen que este reino merezca el honor de que residan aquí más del tiempo necesario para despachar los asuntos del rey, y por ello los despachan con premura. Es natural entonces que muchas personas hayan llegado a pensar que la venida de un gobernador, en un momento inusual, presagia que va a atender un asunto inusual; en especial si es cierta la noticia de que el Parlamento, prorrogado hasta no sé cuándo, fue convocado, revocando la prórroga, a reunirse inmediatamente después de su llegada. Los abogados del otro lado del mar tuvieron la buena suerte de encontrar dos precedentes para justificar este procedimiento extraordinario.

Dando por sentado todo esto, nunca imaginé que un individuo tan insignificante como Wood pudiera tener el mérito suficiente ante el rey y sus ministros para que enviaran al virrey, a toda prisa, a cumplir su encargo.

Tratemos el asunto escuetamente, tal como es, sin los refinamientos de algunas personas con las que nada tenemos que ver. Con base en insinuaciones falsas se otorga una patente con el gran sello de Inglaterra a un tal William Wood para enviar medios peniques de cobre a Irlanda. E1 parlamento irlandés, en previsión de las pésimas consecuencias de dicha patente, apela al rey para que la revoque. Esta apelación se rechaza, y un comité del consejo privado informa a $\mathrm{Su}$ Majestad que Wood cumple las condiciones de su patente. Luego se le deja que haga lo mejor que pueda con sus medios peniques pues nadie está obligado a aceptarlos; el pueblo irlandés, también dejado a su libre voluntad, al unísono resuelve que nada quiere saber de su 
mercadería. Esta descripción escueta de los hechos muestra que el rey y sus ministros están totalmente al margen del asunto, y que lo tenemos que discutir entre él y nosotros. En vista de ello, ¿quién me convencerá de que se va a enviar a un virrey con tanto apremio, antes del plazo normal, y a convocar al parlamento anticipando una prórroga, solo para poner 100.000 libras en el bolsillo de un estafador, para ruina de su reino más leal?

Pero, suponiendo que todo esto sea cierto, ¿con qué argumentos puede el virrey convencer al mismo parlamento que se opuso a este mal con tanto celo y seriedad para que lo apruebe como ley? Estoy seguro de que su opinión sobre Wood y su proyecto no ha cambiado desde la última prórroga. Y suponiendo que se usen los métodos que según los detractores a veces se emplean para ganar votos, es bien sabido que en este reino hay pocos cargos para repartir, y si hubiese más, también es bien sabido a dónde van a parar. Pero como muchos de vosotros nada sabéis de los asuntos de vuestro país, os revelaré algunas de las razones por las que se dispone de tan pocos cargos en este reino. Aquí todos los cargos importantes de por vida son propiedad de quienes obtuvieron el derecho de sucesión, en general partidarios de los gobernadores, o personas que tenían intereses en la corte de Inglaterra. Por ejemplo, Lord Berkeley de Stratton posee el importante cargo de Presidente de la sección civil del Tribunal de Apelaciones; Lord Palmerston es Recaudador de Deudas, un cargo de 2.000 libras al año. Un tal Dodington, secretario del conde de Pembroke, pidió el derecho de sucesión del cargo de Archivista de los Pergaminos del Tesoro, que reporta 2.500 libras al año y hoy disfruta por la muerte de Lord Newton. El señor Southwell, Secretario de Estado, y el conde de Burlington, Tesorero Mayor de Irlanda, lo son por herencia. Y estos son solo unos pocos de los muchos que me han contado y que no recuerdo. Además, el derecho de sucesión de algunos cargos se concede de ese mismo modo mientras se ejercen. Esta situación, entre muchas otras, distingue a Irlanda de las demás naciones de la Tierra, y hace tan difícil conseguir un empleo civil que el señor Addison se vio obligado a comprar un oscuro cargo llamado Guardián de los Registros, en la Torre de Bermingham, de 10 libras al año, y a conseguir un salario anexo de 400 libras, aunque todos los registros que allí se guardan no valen media corona bien sea por curiosidad o por uso. Y hace poco vimos que uno de los secretarios favoritos ${ }^{8}$ descendió a Maestro de Ceremonias, un cargo que ha engrandecido por medio del crédito y la extorsión. Nada digo de la Subtesorería,

${ }^{8}$ El señor Hopkins, secretario del duque de Grafton. 
de unas 9.000 libras al año, ni de los inspectores de rentas, cuatro de los cuales viven en Inglaterra, porque creo que a ninguno de ellos se le ha otorgado el derecho de sucesión. Lo irónico es que he sabido que estos funcionarios absentistas a veces se oponen a los intereses de Irlanda como si no le debiesen ni cuatro peniques.

Confieso que a veces he estado tentado a desear que el proyecto de Wood tenga éxito porque he imaginado con placer que nos llegaría una animada banda de señores y escuderos, pensionistas de ambos sexos y funcionarios civiles y militares, y que viviríamos juntos como mendigos alegres y sociables; con la única desventaja de que no tendríamos carne que comer ni ropa para vestirnos, a menos que nos contentásemos con andar en cota de malla o comer bronce, así como los avestruces comen hierro.

Retorno de esta digresión al tema central. Creo que ahora estaréis convencidos de que si el parlamento de Irlanda se dejase tentar como cualquier otra asamblea cristiana de una milla a la redonda (que Dios no lo quiera), los administradores fracasarían necesariamente por falta de herramientas para trabajar. Pero os daré una razón más: suponiendo que se crearan cien empleos nuevos, para gratificar a los que se dejasen tentar, persistiría una dificultad insuperable. Pues, hasta donde sé, la moneda no es liberal ni conservadora, ni del partido del campo ni del de la ciudad; y no es improbable que un caballero prefiriese vivir en su propiedad, que le produce oro y plata, y no de un empleo cuando la renta y el salario se le pagan con cobre de Wood, con un descuento de más del 80 por ciento.

Por esta y por otras muchas razones estoy seguro de que no debéis sentir el más mínimo temor por la súbita llegada del señor virrey ${ }^{9}$, mientras mantengamos nuestra enérgica disposición, que quizá no pueda ser alterada por ninguna tentación posible. $Y$ si, como he afirmado a menudo con base en las mejores autoridades, la ley no da a la corona la facultad de imponer a sus súbditos ninguna moneda, excepto la esterlina, mucho menos la de delegarla en otro.

Todo esto lo digo con sumo respeto por la persona y la dignidad de su excelencia Lord Carteret, cuyo carácter me fue descrito hace poco por un caballero que lo conoce desde que nació. Ese caballero lo describe como un joven de grandes cualidades, excelente educación, vida ordenada, y mucho espíritu y vivacidad. Como he oído, siempre ha estado empleado en el extranjero. Fue primer secretario de Estado, y ahora, a una edad de casi 37 años, fue nombrado virrey de Irlanda.

\footnotetext{
${ }^{9}$ Lord Carteret, después conde de Granville.
} 
Este reino tiene razones para esperar de este gobernador tanta prosperidad como puede esperar en circunstancias tan desalentadoras.

Es de hecho cierto que en nuestros recuerdos hubo gobernadores de tal destreza que provocaron hechos de terribles consecuencias para este reino, por su poder sobre quienes tenían cargos y su habilidad para manipular y engañar a los demás con juramentos, afabilidad y aun con banquetes. Si el cobre de Wood se hubiese pretendido acuñar en aquellos tiempos es obvio imaginar los métodos que se habrían empleado. Se habría dicho llanamente a los subalternos cuál era el servicio que se esperaba de ellos, so pena de poner los asuntos públicos en manos más obedientes. A otros se les habría seducido con promesas. A los caballeros rurales, además de buenas palabras, vino de Borgoña y reuniones privadas, quizá se les habría insinuado que, así no fuese una obligación, se vería favorablemente que aceptasen la patente real y si sobrevenían inconvenientes después los compensarían con otras mercedes y favores, que considerasen si era prudente y seguro disgustar a Inglaterra, que mejor pensasen en buenas leyes para fomentar el comercio y dar trabajo a los pobres, en posibles medidas contra el papismo y en cómo unir a los protestantes. Habrían hecho el compromiso solemne de no acuñar más de 40.000 libras de su moneda, todas de la mejor clase y el mayor peso, a cambio de las cuales entregaríamos nuestras manufacturas, y mantendríamos el oro y la plata en casa. Y en el momento adecuado quizá se habría difundido el aviso oportuno de una invasión, lo cual es un gran pretexto para reducir las fricciones en los procedimientos públicos. Y se nos habría dicho que no había que crear diferencias cuando el reino estaba en peligro.

Os digo que estos métodos y otros similares se habrían utilizado en tiempos de corrupción para que dejásemos entrar este diluvio de bronce. Y si estoy seguro que ni siquiera entonces lo habrían logrado, mucho menos bajo la administración de una persona tan excelente como Lord Carteret, en un país donde las personas de todas las clases, partidos y confesiones están convencidas, al unísono, de que en el momento en que se acepte esa execrable moneda llegará para siempre la ruina total para ellas y su posteridad. Pues cuando empiece a circular no se podrá limitar a una cantidad pequeña o moderada, así como la peste no se puede limitar a unas pocas familias, y ningún poder terrenal puede hacerlo, así como ningún licor puede devolver la vida a un cadáver.

Hay una circunstancia agradable en esta oposición universal al señor Wood: las personas que nos han enviado de Inglaterra para ocupar vacantes eclesiásticas, civiles y militares están todas de nuestro lado. En 
virtud de una extraña revolución, el dinero, la gran causa de división en el mundo, ha unido al pueblo más dividido. ¿Quién dejaría de ganar 100 libras al año en Inglaterra (un país de libertad) a cambio de que le paguen 1.000 en Irlanda con las monedas de Wood? E1 caballero al que acaban de nombrar Primado ${ }^{10}$ nunca dejaría su escaño en una cámara alta inglesa ni sus prebendas en Oxford y Bristol, de 1.200 libras anuales, por una suma nominal cuatro veces mayor en Irlanda, pero que no tiene ni la mitad de ese valor. Espero que, al menos en este punto, este caballero sea tan buen irlandés como cualquiera de sus hermanos o como los que tuvimos la mala fortuna de nacer en esta isla. Pues como dice el refrán, quienes no vienen aquí a aprender la lengua jamás cambiarían un país mejor por uno peor, y además para recibir cobre en vez de oro.

Otra calumnia difundida por Wood y sus emisarios es que al oponernos a él revelamos una inclinación a liberarnos de nuestra dependencia de la corona de Inglaterra. Observad cuán importante se cree este William Wood y cómo involucra el bienestar público de dos reinos en su interés personal. Primero, todos los que se niegan a aceptar su moneda son papistas, pues según dice solo los papistas se han unido contra él. Segundo, todos ellos impugnan la prerrogativa del rey. Tercero, están dispuestos a rebelarse. Y cuarto, van a liberarse de la corona de Inglaterra, es decir, van a elegir otro rey, porque esta expresión no puede tener otro significado, aunque algunos pretendan soslayarlo.

Y esto me da la oportunidad de explicar a quienes lo ignoren otro punto que a menudo me oprime el corazón. Cuando en un discurso mencionamos las palabras libertad y propiedad, quienes vienen de Inglaterra y algunos irlandeses débiles de espíritu menean la cabeza y nos dicen que Irlanda es un reino dependiente, como si con esa expresión pretendieran decir que el pueblo de Irlanda se encuentra en un estado de esclavitud o dependencia diferente del estado en que se encuentra el pueblo de Inglaterra, aunque la expresión reino dependiente es un término moderno del arte de la política y, como me han dicho, desconocido para todos los antiguos civilistas y tratadistas del gobierno. Irlanda es, por el contrario, una corona imperial, como la llaman algunos estatutos, que solo depende de Dios, es decir, un reino del rango más alto que se pueda conferir. Por tanto, la expresión reino dependiente solo se puede interpretar en el sentido que le atribuye el estatuto redactado en Irlanda en el trigésimo tercer año del reinado de Enrique VIII, por el cual “El rey y sus sucesores serán reyes imperiales

${ }^{10}$ E1 doctor Hugh Boulter.

Revista de Economía Institucional, vol. i7, N. ${ }^{\circ}$ 32, Primer semestre/2oi5, Pp. 35 I-374 
de este dominio, unidos y ligados a la corona de Inglaterra”. Revisé todos los estatutos ingleses e irlandeses sin encontrar ninguna ley que haga a Irlanda más dependiente de Inglaterra de lo que Inglaterra depende de Irlanda. De hecho, estamos obligados con ellos a tener el mismo rey y, en consecuencia, ellos están obligados con nosotros a tener el mismo rey. Y puesto que esa ley fue redactada por nuestro propio parlamento, nuestros antepasados no eran tan cándidos (fueren cuales fuesen en el reino anterior) que se sometiesen a sí mismos a no sé qué dependencia, de la que hoy se habla, sin fundamentarse en la ley, la razón o el sentido común.

Se puede pensar de otra manera, pero yo, M. B., pañero, quiero ser exceptuado, porque declaro que, después de Dios, solo dependo del rey mi soberano y de las leyes de mi propio país, y que estoy tan lejos de depender de las gentes de Inglaterra que si alguna vez se rebelasen contra mi soberano (que Dios no lo quiera), estaría dispuesto, a la primera orden de Su Majestad, a empuñar las armas contra ellas, así como algunos de mis compatriotas las empuñaron contra los suyos en Preston. Y si tal rebelión triunfase e impusiese al pretendiente en el trono de Inglaterra, me arriesgaría a transgredir ese estatuto y a perder hasta la última gota de mi sangre para impedir que fuese rey de Irlanda ${ }^{11}$.

Es de hecho cierto que, en nuestros recuerdos, los parlamentos de Inglaterra a veces asumieron la facultad de coartar este país con leyes decretadas allí, a las que primero se opuso abiertamente (si la verdad, la razón y la justicia se pueden oponer) el famoso señor Molineux, un caballero inglés nacido aquí, así como algunos de los grandes patriotas y los mejores liberales de Inglaterra, pero la pasión y el ansia de poder prevalecieron. De hecho, los argumentos de ambas partes eran irrefutables. Porque, en razón, la definición de esclavitud es todo gobierno que carezca del consentimiento de los gobernados, mientras que, en la práctica, once hombres bien armados vencerán a uno solo en mangas de camisa. Pero ya he dicho que quienes han utilizado el poder para coartar la libertad han ido tan lejos que incluso les mortifica el derecho a quejarse; aunque, hasta donde se sabe, nunca se ha impedido que un hombre sometido al potro de tortura grite tan alto como pueda.

$\mathrm{Y}$ así como tendemos a desanimarnos por temores racionales, también tendemos a animarnos por vanas esperanzas (de acuerdo con la naturaleza de nuestro cuerpo cuando enfermamos). Hace unos días se dijo que, en Inglaterra, alguien autorizó a una segunda persona

${ }^{11}$ Este párrafo se interpretó como un grave delito. 
para que escribiera a una tercera, en Irlanda, y nos asegurara que no se nos intranquilizaría más con esos medios peniques. Y se informa que lo hizo la misma persona ${ }^{12}$ de quien se dijo hace unos meses que había jurado que nos los embutiría en la garganta (aunque dudo que se nos atascaran en el estómago). Pero no es asunto nuestro cuál de esos informes es cierto o falso. Porque en este punto nada tenemos que ver con los ministros ingleses, y lamentaría que dejásemos en sus manos la solución o el cumplimiento de esta injusticia, pues el informe del comité me colmó la paciencia. La solución está completamente en vuestras manos y por ello me desvié un poco del tema para refrescar y mantener ese ánimo que tan oportunamente surgió entre vosotros, y para que veáis que por las leyes de Dios, de la naturaleza, de las naciones y de vuestro propio país sois y debéis ser un pueblo tan libre como vuestros hermanos de Inglaterra.

Si los panfletos que Wood y sus acólitos publicaron en Londres en defensa de su causa se reimprimiesen aquí, y se pudiese persuadir a nuestros compatriotas para que los lean, os convenceríais de su perversa intención más de lo que jamás pueda deciros. En resumen, los escritos de quienes contrata para justificar su proyecto me hacen imaginar que es un perfecto santo, en comparación con lo que parece ser. $Y$ es tan diestro en ese campo (dejo que otros adivinen la razón) que ningún impresor de Londres se atreve a publicar un escrito en favor de Irlanda, y aquí aún nadie se ha atrevido a publicar algo en su favor.

Hace unos días me enviaron un folleto de casi cincuenta páginas impreso en Londres, escrito en favor del señor Wood. No vale la pena responderlo porque probablemente nunca se publicará aquí. Pero me dio la oportunidad de reflexionar sobre la desdicha en que nos encontramos y de que el pueblo inglés nada sepa de nuestra causa; lo que no es extraño, porque es un asunto que no le preocupa ni lo más mínimo, y quizá solo sea un tema de charla de café cuando no tiene otra cosa de qué hablar. Tengo razones para pensar que ningún ministro jamás se tomó la molestia de leer un escrito en defensa nuestra, pues supongo que sus opiniones ya están determinadas y se formaron totalmente con base en los informes de Wood y sus cómplices; porque de no ser así sería imposible que alguien tuviese el descaro de escribir un folleto como el que mencioné.

Nuestros vecinos, cuya inteligencia está al mismo nivel que la nuestra (y que quizás no sea una de las más sobresalientes), sienten gran desprecio por muchas naciones, y en especial por Irlanda. Nos

${ }^{12}$ E1 señor Walpole, después conde de Oxford. 
consideran una especie de irlandeses salvajes a quienes nuestros ancestros conquistaron hace cientos de años. $\mathrm{Y}$ si os describiese a los bretones tal como eran en tiempos de César, cuando se pintaban el cuerpo o se vestían con pieles de animales, yo obraría en forma tan razonable como nuestros vecinos. Pero en relación con el litigio actual es imposible disculparlos porque, como solo escuchan a una de las partes, y no tienen ni siquiera la oportunidad ni la curiosidad para examinar lo que dice la otra, creen una mentira simplemente por comodidad y concluyen que como el señor Wood actúa como si tuviese poder, la razón también está de su lado.

Por ello, para que veáis la forma en que Wood y sus partidarios presentan este litigio en Inglaterra me pareció adecuado extractar algunas de las falsedades más notorias de ese panfleto, tanto con respecto a los hechos como a los razonamientos. El conocimiento de estos hechos confirmará a mis compatriotas sus buenas razones cuando comparen los argumentos de ambas partes y vean que sus enemigos están equivocados.

Primera. El autor afirma categóricamente que los medios peniques de Wood circularon entre nosotros durante varios meses, con el consentimiento de todo el pueblo, sin que nadie los rechazara, y que todos nos sentíamos felices de tenerlos.

Segunda. Afirma que solo empezamos a sentir aversión por las monedas cuando algunos irlandeses astutos con mala intención se opusieron a la patente de Wood para conseguir otra para ellos.

Tercera. Que quienes empezaron a oponerse a la patente de Wood fueron quienes pretendían conseguir otra en su propio beneficio.

Cuarta. Que nuestro parlamento, nuestro consejo privado, el alcalde y los concejales de Dublín, los grandes jurados y los comerciantes, en suma que todo el reino, incluidos los perros (como dice literalmente), estaba satisfecho con esos medios peniques, hasta que fue incitado por esas pocas personas malintencionadas.

Quinta. Dice sin reato que todos los que se opusieron al medio penique eran papistas y enemigos del rey Jorge.

Hasta aquí estoy seguro de que incluso los más ignorantes podréis jurar con seguridad, basándoos en vuestro propio conocimiento, que el autor dice grandes mentiras en todos estos puntos. Para el reino entero es tan evidente que la verdad es exactamente la contraria que, si fuese necesario, conseguiríamos 500.000 firmas para confirmarlo.

Sexta.Pretende convencernos de que si vendiésemos cinco chelines de bienes y manufacturas nuestras por dos chelines y cuatro peniques de cobre, aunque sea cobre de mala aleación y aunque pudiésemos 
conseguir cinco chelines de oro y plata por dichos bienes, nos sería más provechoso aceptar los dos chelines y cuatro peniques de cobre.

Y, por último, con autorización de Wood, nos hace una oferta tramposa: si por nuestros productos obtenemos 200.000 libras en sus medios peniques, y le pagamos un interés del tres por ciento durante treinta años sobre 120.000 libras (la suma que él calcula que la acuñación añade al valor intrínseco del cobre) por prestarnos su moneda, después de ese tiempo nos dará moneda buena a cambio de los medios peniques que nos queden.

Permitid que aclare esta oferta hasta donde me sea posible, para demostrar la insoportable villanía y el descaro de ese incorregible sinvergüenza. Primero (dice él) enviaré 200.000 libras de mi moneda a vuestro país: calculo que el valor real del cobre es de 80.000 libras y os cobro 120.000 libras por la acuñación; como veis os presto 120.000 libras durante treinta años, por las que me pagaréis el tres por ciento, es decir, 3.600 libras por año, lo que en treinta años sumará 108.000 libras. Cuando expiren esos treinta años, devolvedme mi cobre y os daré buena moneda a cambio.

Esta es la propuesta que nos hace Wood en ese panfleto, escrito por uno de sus testaferros, quien se supone que es ese infame Coleby, uno de los que juraron por él en el consejo, procesado por robar al tesoro público de Irlanda cuando era secretario subalterno.

Con esta propuesta Wood recibirá 200.000 libras en bienes o en esterlinas por un cobre que él valora en 80.000 libras, aunque en realidad no vale ni 30.000 libras. También recibirá 108.000 libras de intereses. Y cuando, dentro de treinta años, nuestros hijos devuelvan sus medios peniques a sus albaceas (pues es probable que antes de ese tiempo ya se haya ido al lugar que se merece), los albaceas las rechazarán razonablemente por ser malas y falsas, como ciertamente lo serán, igual que los millones de monedas de su acuñación.

Creo que me agrada un comerciante como este, que nos corrige los precios todos los días, como sucede con la factura holandesa, que cuando reclamamos porque es exorbitante y nada razonable, el mercader la aumenta añadiendo nuevos artículos.

Aunque este y otros panfletos similares que Wood publicó en Londres son del todo desconocidos aquí, donde nadie podría leerlos sin sentir suma indignación, como permitiría el desprecio, consideré adecuado daros una muestra de cómo emplea su tiempo este hombre, de cómo batalla solo, sin que nadie lo contradiga, mientras que nuestros pocos amigos de Londres se sorprenden de nuestro silencio y los ingleses en general, si alguna vez piensan en este asunto, atribuyen 
nuestro rechazo a la insubordinación y al desafecto, tal como a Wood y a sus testaferros les place presentarlo.

Pero aunque no se permita publicar nuestros argumentos en Inglaterra eso no tendrá grandes consecuencias. Dejad que Wood persuada a las personas de allí de que debemos aceptar su moneda y que yo convenza a las de aquí de que deben rechazarla, so pena de nuestra completa ruina. Y que él haga entonces lo mejor y lo peor que pueda.

Antes de terminar debo pediros, con toda humildad, que me permitáis decirle al señor Wood que es culpable de gran indiscreción por haber instigado a mencionar con tanta frecuencia y de tal manera el nombre de una persona tan honorable como el señor Walpole a propósito de este asunto. Un breve escrito impreso en Bristol y reimpreso aquí informa que el señor Wood dijo que le sorprendía el atrevimiento y la insolencia de los irlandeses al rechazar su moneda, y qué haría el señor Walpole cuando llegase a la ciudad. Por cierto, aquí está equivocado porque quienes la rechazan son los verdaderos ingleses de Irlanda; aunque damos por descontado que también la rechazarán los irlandeses cuando se les pregunte. En otro escrito, tramado por él, se dice literalmente que el señor Walpole nos embutirá su cobre en la garganta. $Y$ que a veces ha dicho que si no aceptamos estos medios peniques tendremos que comernos nuestras abarcas. $Y$ en un boletín de noticias de ayer leemos que ese gran hombre juró hacernos tragar su moneda en bolas de fuego.

Esto trae a mi mente la conocida historia del escocés que cuando recibió la sentencia de muerte que lo condenó a ser ahorcado, decapitado, descuartizado, eviscerado y menudencias similares, exclamó: “Qué necesidad hay de tanta culinaria?”.Y creo que tenemos razones para hacer esa misma pregunta. Porque si creemos a Wood, se nos ha preparado un banquete, y veis el costo de la factura; lamento que se haya olvidado la bebida, pues fácilmente se nos podría ofrecer plomo fundido y alquitrán ardiente.

¡Cuán viles son estas palabras para ponerlas en boca de un gran consejero que goza de la más alta confianza del rey, y al que se considera primer ministro! Si el señor Wood no puede dar una imagen mejor de sus patronos, el día en que me den un alto cargo no toleraré que asista a mi posesión. Ese no es el estilo de un gran ministro; esas palabras despiden el aroma de la marmita y el fogón y provienen más bien de la herrería de Wood.

En cuanto a la amenaza de que tendremos que comernos nuestras abarcas, no debemos afligirnos, pues si su moneda llegase a circular este calzado inelegante dejaría de ser una vergüenza nacional porque 
en el reino ya no quedarían ni zapatos ni abarcas. Aquí se detecta claramente la falsedad del señor Wood, pues estoy seguro de que en toda su vida el señor Walpole jamás ha oído hablar de abarcas.

Igual de improbable es la historia de hacernos tragar los medios peniques en bolas de fuego. Porque para ejecutar esa operación habría que fundir todas las monedas y todo el metal del señor Wood y moldear a fuego vivo bolas huecas no muy grandes, para que pueda tragarlas una garganta de tamaño razonable. Ahora bien, el metal que preparó y ya acuñó equivale como mínimo a 50.000.000 de medios peniques que deberían tragar 1.500 .000 personas; de modo que si en cada bola hubiese dos medios peniques, cada persona de este reino tendría que tragarse unas diecisiete bolas de fuego vivo, y para administrar esa dosis no puede haber menos de 150.000 operadores, calculando uno por cada treinta personas, lo que es razonable considerando los remilgos de algunos estómagos y los lloriqueos de los niños más pequeños. Ahora bien, sujeto a correcciones de personas más entendidas, calculo que la dificultad y el costo de ese experimento excederían al beneficio. Por ello, creo que este informe es espurio o, al menos, una nueva treta del señor Wood, quien se lo atribuyó a un ministro de Estado para que recibiera mejor atención en Irlanda.

Ahora demostraré, más allá de toda duda, que el señor Walpole se opone a este proyecto del señor Wood y está totalmente en favor de Irlanda, con este argumento único e irrefutable. En opinión de todos, el señor Walpole es un hombre sensato y un ministro capaz que en todas sus actuaciones obra en el verdadero interés del rey, su señor, y que su integridad está por encima de toda corrupción y su fortuna por encima de toda tentación. Considero entonces que por ese lado estamos totalmente a salvo y que nunca tendremos que enfrentarnos a un poder tan formidable, y que se nos dejará poseer en paz nuestras abarcas y nuestras patatas, tan lejos del trueno como lo estamos de Júpiter ${ }^{13}$.

Queridos compatriotas, soy vuestro afectuoso compañero súbdito, compañero de sufrimiento y humilde servidor.

M. B.

13 de octubre de 1724

${ }^{13}$ Procul a Jove, Procul a fulmine. 
A la llegada de Lord Carteret, poco después de la publicación de esta carta, su excelencia y el consejo emitieron una proclama que ofrecía una recompensa de 300 libras por delatar al autor. El impresor Harding fue encarcelado y se ordenó levantar un acta de acusación contra él [Nota de los editores de la edición de 1801]. 